\title{
Computer Applications Educational Reform and Laboratory Practice and Exploration in Higher Education
}

\author{
Yanbo $\mathrm{Wu}^{1}$, Dawei Xiang ${ }^{2, *}$ \\ ${ }^{1}$ Hubei Police College Experiment Center, Hubei University of Police, P.R. China \\ ${ }^{2}$ Department of Electronics Engineering, Hubei University of Police, P.R. China \\ ${ }^{*}$ Corresponding author Email: 2914516980@qq.com
}

\begin{abstract}
In the booming higher education today, lab construction has become an important job for personnel training in universities. Universities must accelerate the experimental teaching reform, strengthen its laboratory management and community-oriented development to cultivate innovative talents. In this paper, the author with over years of experience in teaching and managing computer laboratories has explored and done research regarding the computer experiment teaching and laboratory management in colleges and universities under the new broader trends.
\end{abstract}

Keywords: Computer; experimental teaching; laboratory construction

In recent years, information technology, hardware and software updates have developed at a frenzy pace, but due to the continuous expansion of enrollment in colleges and universities, increasing enrollment, computer labs undertake the task of teaching have become more and more difficult. Experimental teaching system, construction of the experimental system, teaching staff, management innovation and other aspects are challenges.

In teaching activities, for students to learn experimentally is an important part of creative ability, it can not only verify the theoretical knowledge learned in the classroom to enhance concepts, but more importantly to train students to analyze problems and problem-solving skills. Therefore, university laboratory management system reform and innovation is imperative to comply with the requirements of the times, build a scientific and rational experimental teaching system, laboratory management innovation, and improve the management level.

\section{Building scientific and rational experimental teaching system}

Experimental teaching is to train students 'ability to deepen students' understanding of the basic theory, and to access an important part of the practice of science knowledge. Experimental Teaching Reform of University Laboratory is a difficult job. The current experimental teaching reform must break the traditional experimental teaching mode, in accordance with the requirements of quality education, to cultivate students' creative ability as the main line, to build a people-oriented multi-level experimental teaching system [1]. To completely change the past, the teaching of the theory of heavy, light experimental and practical approach to highlight the important role of experimental and practical teaching computer professionals Training.

\subsection{Basic Principles}

(1) Build a complete and advanced laboratory environment;

(2) In the course of teaching at every stage as the driving force, set up high-quality, content-rich strata experiment for students to carry out comprehensive and implement innovative experiment

(3) Prepare multi-dimensional, multi-level, high-level experimental teaching materials; 
(4) Strengthen management objectives, develop the students' hands-on experiments and problem-solving skills and consider exam reform measures;

(5) construction of a level, reasonable structure, various types of fully staffed experimental teaching team.

\subsection{Deepening Experimental Teaching Reform}

Education is the basis for the training of personnel, economic and social development, and play the pilot role in global development. Experimental teaching as an integral part of education in the deepening education reform and promote quality education in the process, should be the perfect student structures and the ability to structure knowledge as the overall goal of training creative talent around the overall objective of the experiment teaching reform [2]. Experimental teaching can be "laying the foundation" and "breaking up layers / hierarchical" teaching model, by focusing on basic experiment, the addition of virtual experiment, experiment and broaden the application of experimental methods to encourage autonomy, gradually formed from low to high, from basic to front, from imparting knowledge to foster innovation of new teaching framework.

(1) The transition from basic experiments from theory to engineering applications comprises of culturing knowledge and ability; basic experiment should focus on a solid foundation.

Focus on training students to correctly use the basic experimental operation, experimental methods and conventional equipment to achieve the basic experimental skills training to consolidate purpose theory of knowledge. So that the basic experiment experimental teaching system has become an important part, and for the latter to complete an independent comprehensive design experiments to lay a solid foundation. Experiment in groups, and strive to create a good learning environment for improving student skills test. The computer-based applications in Excel data management and analysis experiments in this experiment not only help high school students to sort the data list screening, classification data summary, PivotTable, page setup and other basic operations, but also to allow students to access databases, data structures basic knowledge, in-depth understanding of its principles.

(2) Experiments with applications.

In this session, teachers will only provide design ideas, specifically designed by the students themselves. Students design drawn up after cross-examination by the teacher, the implementation of their own design, commissioning, until the completion of the whole process, and then write a summary report. Experimental problems, teachers should analyze the reasons with them together to improve. Experiments are allowed to fail. When assessing the results of a given experiment results, the focus will not only be assessment results, but also clear thinking to experiment with unique insight, innovative experimental design, experimental results have improved given high marks. The computer network experiment in the application server to build and set up local area network physical experiment. Among LAN set-based experiments, it is required that students master the method of formation of local area network, making a straight and twisted cross twisted pair, with a network cable tester made correctly.

(3) Virtual experiment is used to guide students to use new technologies and new methods to analyze the problem and to allow students to carry out various comprehensive design experiments.

This "actual situation, carrot and stick" experimental teaching methods, students and the creation of an imaginary space, but also provide them with an excellent platform to showcase their talent. Virtual experiments allow students to come to understand through this link: creation is not an unattainable thing, as long as they are good at thinking, good at summing up experience, innovation and creativity for everyone. Pilot projects such as "digital electronic circuits" course 
experiment in "Traffic Light Control System Design", "Neon control system design," etc., the students in the lab will be able to experience such a feeling similar to the practice of research topics, as well as students who can combine their own requirements and practical problems some new design practice autonomously, and thus exercise their own ability to solve practical problems and applications, innovation and engineering practice ability.

(4) Open Experimentation.

Frame experimental teaching system and adjust the content of the required experimental teaching methods cannot be limited to the curricular training, and must provide students with a more extensive, real-time, innovative ideas and creative space. Students should be encouraged to conduct an open test (also known as autonomous or self-test), it does not have credit, does not take up class hours, completely voluntary, the purpose is for students who are interested to get a deeper level of developmental environment. Experiment Center has specialized in innovative laboratory for students to innovative practice. The laboratory shall be provided a fixed time every week is open to students. Student's topic may be a theoretical or experimental courses on curriculum, but also exploratory research topic. Teachers can guide in guiding them to find information document, and then let students customize design. The apparatus management system is based on Access or MySQL $\backslash$ SQL Sever such as design and production experiments. This purpose of the experiment is to allow students to use the integrated database and application of the principles of course to talk about the content and design skills to develop and design a small application system, application in practice really grasp the functions of the various tools and techniques using a variety of tools and their ability to improve students' hands-on programming, independent thinking, problem-solving skills.

\section{Building Computer Laboratories}

In the laboratory construction and reform, we should adapt to the personnel training "wide caliber, thick foundation, strong practice, large platform" requirements, pay attention to the combination of theory and practical teaching, combining teaching and research, qualified schools should Note that "Gakken production" combination. Undergraduate education is mainly basic education, high-quality experimental teaching must be combined with theoretical teaching, the majority of high-level mechanism from the experimental research, the laboratory should be experimental, teaching, research, industry and Four Combinations unity. This is the guiding ideology of building a very important high-level laboratories. Laboratory construction in general, can be summarized in the following five aspects.

\subsection{Construction of the experimental system}

(1) Depending on the direction of professional schools should set up and train the students the difference between the target and the establishment of experimental teaching system which adapts.

In the design of each experiment, we should consider the main points of the professional fields of knowledge and different schools vastly different experimental conditions, the contents of most of our experiments should be based on easily build experimental environment for Windows and Linux operating systems. Universities can also be conditional on the software and hardware design of complex large-scale experimental high demand. Such as: computer forensics course is to train students in information security professional computer evidence acquisition, analysis and appraisal of the abilities of students should be the focus of teaching. Teaching experimental courses should be in a simulated test environment in the field and teachers should work closely with the actual public security work, carefully designed programs of teaching experimental 
course, the formation of computer forensics Experimental Teaching System. For example, teachers can play a simulation of the implementation of criminals and criminal activities, and let the students experiment environment and forensic tools to carry out forensic investigations for the simulation of the case, to submit a final report as evidence the results.

(2) The establishment of academic research and engineering for basic skills training, grade exams and other non-academic education as the main task of the whole system open experiment.

For example, my school computer lab has been responsible for a large number of computer training class task Provincial Public Security Organization, over the years accumulated a wealth of on-the-job training for the police and teaching experience. In laboratory scale becomes larger, architecture has become more rational environment, we can further expand the scale of training to improve the quality of training. At present electronic police work can be divided into network management and network investigation both for network management in the electronic police can go to the computer network laboratory for study, research and training, and for the network in electronic police investigation you can go to electronic forensics laboratory in-depth study and intensive training. Through various means to the majority of the laboratory group of policemen fully open, so that one can maximize the use of available resources and enhance the combat effectiveness of police officers; through various forms of communication, but also allows to have a more adequate theory of teaching practical basis, but also for the school to create a portion of the profits.

(3) The establishment of laboratory information management system.

Department-based experimental platforms or test center, and experimental and equipment secretarial staff as the basic team, the school built laboratory information NMS. Currently, the only way is the development of digital campus universities, colleges and universities are carrying out major construction and discussion in this regard, the institute has now completed the related construction, such as digital libraries, campus card and other projects. Digital Lab equally imperative, through the construction of laboratory information management systems, on the one hand can be more efficient use of laboratory resources, to promote teaching and research work; on the other hand, for the construction of a platform for self-promotion, expand their horizons, the entire contact world is helpful.

\subsection{Lab Room Management Model Innovation}

University Laboratory and open sharing of large equipment, not only the investment efficiency requirements, more important is the need of training high-level innovative talents and scientific research. We should establish and improve teaching laboratory opening mechanism for an open fund, and improve the utilization efficiency of the laboratory. Most basic experiment platform enables open all day and part of the professional laboratory should make full use of network technology to achieve all-round opening time, space, experimental projects; also can establish a sound mechanism for large-scale equipment to increase the share of equipment opening Fund efforts, specifications maintenance fund management approach, gradually open around the clock on the analysis and testing equipment certified machine.

Our department has a computer lab information security, software engineering, computer networks, computer forensics and other 10 specialized laboratories nearly 1,000 computers. One of the biggest public security information technology room 230 computers. In order to facilitate unified management and maintenance of the engine room, and each room is equipped with a control system, on the teacher and student machines installed a very domain of electronic classroom management software. Teacher by room control system to control any device to switch between the media, to organize activities by teachers teaching machines, control teaching 
process. Electronic pole domain enables teaching demonstration, group teaching, group discussion, Quiz, file transfer, screen broadcast, remote switch, remote setting, monitoring, broadcast and other functions. Such a learning environment presents both forms of teaching content, but also provide a wide range of rich learning resources to support student autonomy, cooperation, explore learning activities.

\subsection{Experimental Technology Team}

Any advanced equipment, laboratory instruments, have to rely on people to master and use. Modern experimental teaching needs knowledgeable and skilled teachers to guide and manage. Establish a high-level academic and experimental techniques, structural optimization, teaching and research and laboratory management combining with dedication, innovation, experiment relatively stable teaching force without delay.

(1) The institutions should take effective measures in the laboratory team building, ability and political integrity of the teachers in the laboratory to leadership positions.

Adjustment test team, optimizing titles and educational structure, the number of high education and professional levels and academic standards, experienced, high level of expertise of teachers to enrich the experimental teaching and technical team, strengthening experimental teaching technology, increase the intensity of experimental equipment maintenance and repair; Laboratory technician adjustment policies and treatment in the treatment and theory course teachers alike, care about their work, study and life, inspire their dedication enthusiasm, improve business and management level, experimental Teaching quality.

(2) Strengthen the training of technical personnel for the experiment.

To ensure the level of experimental teaching continues to improve, to continuously optimize the experimental team, to improve the political and professional quality of laboratory personnel, provide training opportunities, seminars and study tours, etc. for them, continue to learn new equipment, new technology, new methods, and constantly improve experimental teaching and laboratory management.

In 2015 in our department institutional reforms, experimental center post into technical positions and management positions. Which is mainly responsible for technical posts experimental teaching, scientific research experiments and external technical services and other tasks. It should have a university degree or above, or have intermediate professional titles (skilled workers should be the primary level and above). Management positions mainly responsible for management and experimental teaching laboratory management tasks, including experimental teaching management, materials management, security management, basic information management. It should have a university degree or above, and have relevant work experience. Focus on laboratory personnel job training, in-service training of teachers to study in practice both selected to participate in short-term training and equipment seminars. There are suppliers of technical representative to the Institute to operate demonstration and training in the use of instruments and equipment.

\subsection{Laboratory system reform to improve the rules and regulations}

Flexible, standardized and scientific management system, establish and improve rules and regulations document is to give full play to the teaching lab, standardized laboratory management, improve management, and orderly conduct experimental teaching important guarantee [4]. Departmental computer lab, are responsible for the department and the student's computer science curriculum experiment, students and graduate design course design, graduation practice, experimental teaching tasks, often receive a variety of training tasks Provincial Public Security arrangements per semester nearly 10,000 students and policemen on board the heavy 
task, difficult to manage. To ensure the smooth development of experimental teaching, laboratory and play its due role, we must strengthen the management system reform experiment. School of Management do not only help, but also conducive to the implementation of experimental teaching., Efforts should be difficult to translate into favorable conditions, more front-line police officers and experienced in-depth exchanges, more grass-roots public security to conduct research, they need some What knowledge and skills, we will study what knowledge and skills; they need what kind of students we kind of student culture. And these are penetrated into every sense of laboratory equipment and laboratory staff every go. But also to improve the teaching documents and regulations, laboratory work to promote efficient, orderly development and management standardization.

\section{Conclusion}

The rapid development of information technology, hardware and software update speed is also creating new technical and management issues, which will always be endless, and only in the laboratory in the management of constantly summing up experience, can we improve the operational capacity and management level, continuous innovation, to make computer laboratory building work to a new level.

\section{Acknowledgement}

It is a project supported by Hubei Police Academy teaching and research project (JYKT2015019, JYYB2015007); Hubei Police Academy Sciences key project (2014GZ022,2012AT006).

\section{Bibliography}

[1] Xiaoyu Wei, Chen Chi University Laboratory Practice Management System [J] Experimental Technology and Management, 2011 (8): 118-121

[2] Wu Menu. Strengthening Research and Practice of Undergraduate Teaching Experiment Laboratory Research and Exploration, Vol. 24 No. 11, 2005.11.

[3]] Li Tian Practice and Exploration of Computer Laboratory of University Innovation Model [J] experiment teaching instrument, 2007 (3): 49-50

[4] Zhang Lilian exploration based information tools Laboratory Management Mode [J] Laboratory Research and Exploration, 2010 (7): 152-15 